time of his or her arrest. There is no evidence that medical records are included.

As long as the purpose of storing knowledge about contagious disease affecting a convicted person or one suspected of having committed a crime is limited to the objectives outlined above, there can be little antipathy to the policy on grounds of principle. Moreover, it could be argued that the police service has not discharged the duty of care it owes to operational police officers if it fails to provide warnings of contact with known infective people. Although the police understand that having such knowledge may not protect them against infection, it allows them to be counselled and possibly given prophylaxis with zidovudine when their work has put them at risk. ${ }^{9}$

The situation is comparable to that of forensic pathologists performing necropsies on victims of violence. ${ }^{4}$ No one would deny them the advantages of knowing whether they were at risk of infection before proceeding. The police are entitled to the same protection; there is no reason why they should not receive it provided that offenders' rights to privacy are protected at the same time. On current evidence, this balance is being achieved.

J K MASON

Professor (Emeritus) of Forensic Medicine

University of Edinburgh,

Old College,

Edinburgh EH8 9YL

1 Srivastra AC, Pinching AJ, Adler MW, Robertson R, Higgs R. Identity cards for patients infected with HIV? $B M 7$ 1987;294:495-6.

2 Gillon R. AIDS and medical confidentiality. BMF $1987 ; 294: 1675-7$.

3 King MB. AIDS on the death certificate: the final stigma. $B M \gamma$ 1989;298:734-6.

4 Sadler DW, Pounder DJ, Urquhart GED, Porter-Boveri M. HIV antibody prevalence in forensic fatalities. BMF 1991;304:1027-8.

5 Attorney General v Guardian Newspapers Ltd (No. 2) [1990] 1 AC 109.

6 W v Egdell [1990] Ch 359.

Lee R. Disclosure of medical records: a confidence trick? In: Clarke L, ed. Confidentiality and the law. London: Lloyd's of London Press, 1990.

8 X v Y [1988] 2 All ER 648.

9 Swinburne L. Infection and violence. In: Mason JK, ed. The Pathology of Violent Injury. 2nd ed. London: Edward Arnold (in press).

\title{
Treatment of elderly patients with breast cancer
}

\author{
Tamoxifen alone is no longer justified
}

Over one third of all breast cancers occur in women over 70 . Although these elderly women have often been excluded from breast cancer trials, women aged 70 have a life expectancy of 14 years. ${ }^{\prime}$ Despite a widely held view that breast cancers in elderly women are less aggressive there is little evidence to support this. ${ }^{23}$

Uncontrolled studies published in the early 1980s suggested that tamoxifen as the sole treatment was effective for elderly patients with breast cancer. ${ }^{+7}$ Since then increasing numbers of elderly patients have been treated in this way. Follow up has usually been short, and one study, which followed up patients for at least five years, has cast serious doubts on the efficacy of tamoxifen alone in these elderly patients. ${ }^{8}$ In that study tamoxifen did not control local disease in $62 \%$ of patients to the time of death or most recent follow up. Only patients whose cancers responded completely to tamoxifen achieved a satisfactory rate of local control at five years.

Although immunocytochemical assays can predict the response to tamoxifen,' deciding with certainty which patients will have a worthwhile response is not possible. Other markers of response, such as epidermal growth factor ${ }^{10}$ and transforming growth factor $\beta 1,{ }^{11}$ are currently being studied.

Two prospective trials compared tamoxifen with surgery in elderly patients and came to opposite conclusions. In a study of patients randomised to surgery or tamoxifen, Gazet et al reported no difference in time to disease progression between the two groups and concluded that tamoxifen was effective as first line treatment. ${ }^{12}$ This study has been criticised because of its small numbers and large proportion of inoperable tumours and because most patients randomised to surgery had wide local excision. This is probably inadequate local treatment, particularly for large tumours. Robertson et al randomised patients to receive either wedge mastectomy with excision of affected nodes or tamoxifen alone. ${ }^{13}$ Significantly more patients receiving tamoxifen required a change of management for local progression of disease.

Only one published trial compared tamoxifen alone with surgery and tamoxifen. ${ }^{14}$ At a median follow up of 42 months patients who had received the combination of surgery and tamoxifen had a small but significant survival advantage. Most patients undergoing surgery had wide local excision; one in four had a mastectomy. After 34 months local recurrence rates were more than five times higher in the patients treated by wide local excision than in those undergoing mastectomy. ${ }^{14}$ A study comparing modified radical mastectomy with wide local excision and tamoxifen reported a survival advantage for the mastectomy group. ${ }^{3}$ This study also showed more local recurrences after wide local excision. Contrary to some proposals ${ }^{15}$ these trials suggest that wide local excision without postoperative radiotherapy is not satisfactory local treatment for elderly patients with breast cancer.

What are the results of mastectomy in these elderly patients? The average mortality in elderly patients undergoing mastectomy is less than $1 \%,{ }^{316-18}$ which has led some authors to suggest tiat elderly patients should be treated by surgery. Simple mastectomy alone in these elderly patients seems associated with an unacceptable rate of axillary relapse when compared with a modified radical mastectomy. ${ }^{318}$ Importantly, modified radical mastectomy does not seem to be associated with a higher postoperative mortality than the lesser operation. ${ }^{3}$ Little justification therefore exists for the continued use of simple mastectomy alone in managing these patients. There are few data relating to treatment of elderly patients with radiotherapy because of the reluctance to treat these patients with this method. ${ }^{2}$ There is no evidence, however, to suggest that they tolerate radiotherapy less well.

Clearly, elderly patients with breast cancer should receive treatment that effectively controls disease long term. The unselected use of tamoxifen alone in such patients is therefore no longer justified. Patients with operable breast cancer who are fit should have either wide local excision and radiotherapy ${ }^{19}$ or a modified radical mastectomy. They should also receive adjuvant tamoxifen as it has been shown to improve the control of local disease and survival in postmenopausal women. ${ }^{2021}$

In patients unfit for a general anaesthetic tamoxifen alone is satisfactory treatment for those whose tumours test positive for oestrogen receptors. This assay is now widely available and can be performed on the same fine needle aspirate as that taken to establish the diagnosis. ${ }^{9}$ Where this assay is not available or when the tumour is negative for oestrogen 
receptors patients should have some other form of local treatment, either wide local excision under local anaesthesia or radiotherapy, or both.

For locally inoperable disease combined radiotherapy and tamoxifen is probably the best treatment. In metastatic disease, knowing the oestrogen receptor status is useful because tamoxifen is unlikely to be effective in tumours that are negative for the receptors. In such patients palliative chemotherapy may provide worthwhile responses without appreciable toxicity. ${ }^{22} 23$

\section{J MICHAEL DIXON}

Senior Lecturer,

University Department of Surgery,

Royal Infirmary of Edinburgh,

Edinburgh EH3 9YW

1 Office of Populations, Censuses and Surveys. 1985-87. London: HMSO

2 Yancik R, Reis LG, Yates JW. Breast cancer in ageing women: a population-based study of contrast in stage, surgery and survival. Cancer 1989;63:976-81.

Fentiman IS. Breast cancer in the elderly. In: Detection and treatment of early breast cancer. London Martin Dunitz, 1991:193-206.

4 Preece PE, Wood RAB, Mackie CR, Cuschieri A. Tamoxifen as initial sole treatment of localised breast cancer in elderly patients. BMF 1982;284:869-70.

5 Helleberg A, Lundgren B, Norin T, Sander S. Treatment of early localised breast cancer in elderly patients by tamoxifen. Br f Radiol 1982;15:511-5.

patients by tamoxifen. Brf Radiol 1982;15:511-5.
Bradbeer J, Kyngdon J. Primary treatment of breast cancer in elderly women with tamoxifen. Clin Oncol 1983;9:31-4.

7 Allan SG, Rodger A, Smyth JF, Leonard RCF, Chetty U, Forrest APM. Tamoxifen as primary treatment of breast cancer in elderly or frail patients: a practical management. $B M \mathcal{J}$ 1985;290:358
8 Horobin JM, Preece PE, Dewar JA, Wood RAB, Cuschieri A. Long-term follow up of elderly patients with loco-regional breast cancer treated with iamoxifen only. Br $\mathcal{F}$ Surg 1991; 78:213-7. Gaskell DJ, Hawkins RA, Sangster K, Chetty U, Forrest APM. Relation between immunocytochemical estimation of oestrogen receptor in elderly patients with primary breast cancer in response to tamoxifen. Lancet 1989;i:1044-6.

10 Nicholson S, Haltrew P, Sainsbury JRC, Angus B, Chambers P, Farndon JR, et al. Epidermal growth factor status associated with failure of primary endocrine therapy in elderly postmenopausal patients with breast cancer. Brf Cancer 1988;58:810-4.

11 Thompson AM, Kerr DJ, Steel CM. Transforming growth factor $\beta 1$ is implicated in the failure of tamoxifen therapy in human breast cancer. Br f Cancer 1991;64:609-14.

12 Gazet JC, Markopoulos CH, Ford HT, Coombes RC, Bland JM, Dixon RC. Prospective randomised trial of tamoxifen versus surgery in elderly patients with breast cancer. Lancet $1988 ; \mathrm{i}: 1679.81$.

13 Robertson JFR, Todd JH, Ellis IO, Elston CW, Blamey RW. Comparison of mastectomy with tamoxifen in treating elderly patients with operable breast cancer. $B M \mathcal{B}$ 1988;297:511-4.

14 Bates T, Rily DL, Hoghton J, Fallowfield L, Baum M. Breast cancer in elderly women: a cancer research campaign trial comparing tamoxifen with tamoxifen and optimal surgery with tamoxifen

15 Reed MWR, Morrison JM. Wide local excision as the sole primary treatment in elderly patients with carcinoma of the breast. Br f Sury 1989;76:898-900.

16 Amsterdam E, Birkenfeld S, Gilad A, Krispin M. Surgery for carcinoma of the breast in women

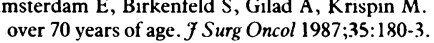

17 Svastics E, Sulyok Z, Besznyk I. Treatment of breast cancer in women older than 70 years. f Surg Oncol 1989;41:19-21.

18 Hunt KE, Fry DE, Bland KI. Breast carcinoma in the elderiy patient: an assessment of operative risk, morbidity and mortality. Am J Surg 1980;140:339-42.

19. Fisher B, Redman C, Porss R, et al. Eight-year results of a randomised clinical trial comparing total mastectomy and lumpectomy with or without irradiation in the treatment of breast cancer. N Englf Med 1989;320:822-8.

20 Noevadex Adjuvant Trial Organisation. Controlled trial of tamoxifen as a single adjuvant agent in the management of early breast cancer. Brf Cancer 1988;57:608-11.

21 Early Breast Cancer Trialists' Collaborative Group. Group systemic treatment of early breast cancer by hormonal, cytotoxis or immune therapy. Lancet 1992;339:1-15, 71-85.

22 Gelman RS, Taylor SG. Cyclophosphamide, methotrexate, and 5-fluorouracil chemorherapy in women more than 65 years old with advanced breast cancer: the elimination of age sirength and toxicity by using dose based on creatinine clearance. F Clin Oncol 1984;2:1404-13.

23 Goldhirsch A, Gelman RS, Gelber RD, Castiglione M. Treatment of breast cancer in elderly patients. Lancet 1990;ii:50́4 (letter)

\section{Managing infants who cry persistently}

\section{Support services need to be developed while promising leads are pursued}

During the first postnatal year persistent crying by apparently healthy babies is a common source of distress among families and referral to health services and has been linked to child abuse. ${ }^{1}$ Three treatments exist: drugs, diet, and changing parental behaviour. Another approach is to help parents cope with the crying rather than to treat it.

Of the various drugs that have been tried, only dicyclomine hydrochloride has consistently proved effective, reducing crying in most cases. ${ }^{23}$ Its manufacturers, however, discourage its use in infants because of reports of adverse reactions and death. A high response to placebo is characteristic of drug studies. ${ }^{+}$

The belief that pain related to digestion (colic) causes crying has produced many reports but little evidence. Gastrointestinal symptoms may also result from rather than cause persistent crying. The possibility that intolerance of cows' milk causes crying in a subgroup of infants has, however, received support from two controlled studies, ${ }^{56}$ although the clinical importance of these findings is not yet clear. Such intolerance seems rare, occurring in about one in 30 infants overall, compared with the one in five referred for persistent crying or colic. ${ }^{167}$ It may occur in both bottle fed infants and breast fed infants (through maternal ingestion of cows' milk).

There is no way of distinguishing the intolerant infants from others who cry persistently. Moreover, although crying improves after treatment, it continues intermittently and at a higher level than normal. ${ }^{5}$ Forsyth recommends that if changes in the formula are contemplated parents should be counselled that the intolerance is probably short lived, so that their baby won't necessarily be "allergic" in the longer term. ${ }^{5}$ Both published studies replaced cows' milk with a hydrolysed casein formula; Lothe and Lindberg caution against using alternatives based on soya. ${ }^{6}$

With regard to parental behaviour, it seems unlikely that most parents of crying babies differ substantially from other parents in their approach to care. For example, maternal experience-a powerful predictor of maternal confidence and behaviour-seems irrelevant: firstborn infants do not cry more.' Similarly, leaving babies to grizzle and settle is common and not a good predictor of later crying levels. ${ }^{8}$ In some cases, however, extremes of parental behaviour or failure to read individual infants' needs may be responsible.

Although studies of behavioural intervention have shown that rhythmic stimulation and movement soothe crying, whether these prevent or reduce persistent crying in the longer term is not known. In a controlled study Hunziker and Barr found that carrying infants for an extra two hours a day from the third postnatal week greatly reduced crying, particularly in the evenings at around 6 weeks of age. ${ }^{9}$ A recent attempt partially to replicate this study in the community, however, was unsuccessful (I St James-Roberts and R G Barr, unpublished findings). Barr and colleagues also found that such carrying was ineffective in treating infants referred for excessive crying. ${ }^{10}$

Rather than modifying carrying, Taubman designed a six point treatment to increase the amount of responsive care and stimulation provided by parents. This proved better than reducing stimulation ${ }^{11}$ or eliminating cows' milk or soya milk. ${ }^{12}$ By contrast, McKenzie found that admission to hospital and "reduced" stimulation lessened crying in a subgroup of referred infants. ${ }^{13}$ As this approach seemed designed to make stimulation more sensitive and contingent rather than to withdraw it, the inconsistency with Taubman's approval may be more apparent than real. Unfortunately, neither researcher provided evidence that the interventions were implemented - the changes in parental behaviour are therefore unknown.

When parental care falls within normal limits the alterna- 